\title{
ARQUITECTURA DEFENSIVA Y URBANISMO EN MATANZAS. UN PROYECTO DE BATERÍA Y DÁRSENA DEL INGENIERO MILITAR CARLOS BENÍTEZ DE 1839
}

\author{
DEFENSIVE ARCHITECTURE AND \\ URBANISM IN MATANZAS. A CARLOS BENITEZ'S \\ PROJECT FOR A BATTERY AND A DOCK OF 1839
}

\author{
IGNACIO J. LÓPEZ HERNÁNDEZ \\ Universidad de Sevilla, Sevilla \\ ilopez7@us.es
}

\begin{abstract}
En su dualidad urbana y defensiva, la ciudad cubana de Matanzas supone un claro exponente de las indagaciones tipológicas y formales con las que se experimentó en territorio cubano a lo largo de sus cuatro siglos de presencia española. En este artículo se aborda tal circunstancia dándose a conocer un proyecto urbanístico y defensivo inédito para la ciudad del ingeniero militar Carlos Benítez de 1839.

Palabras clave: Arquitectura defensiva, Carlos Benítez, Cuba, Matanzas y Urbanismo
\end{abstract}

The Cuban city of Matanzas is one of the most representative examples of urban and defensive experimentations in Cuba during the Spanish presence. In this paper it is studied an example of this circumstance, a project for a battery and a dock for the port of Matanzas, designed by the military engineer Carlos Benítez in 1839.

Keywords: Carlos Benítez, Cuba, Defensive architecture, Matanzas and Urbanism.

Constituida La Habana como uno de los principales puntos articuladores del circuito de la Flota de Indias, no pocos fueron los esfuerzos por hacer de esta ciudad uno de los enclaves más controlados militarmente del territorio americano. No sólo la bahía capitalina y su entorno inmediato fueron centro de las preocupaciones de gobernadores e ingenieros militares, sino que pronto se advertirá el peligro de tener desguarnecidos parajes más lejanos que igualmente se probaron 
como claves para el control del territorio. Es así como tiene su origen la construcción a partir de 1693 del Castillo de San Severino de Matanzas, fortaleza aún deudora de los planteamientos que trajeron la modernidad a las edificaciones defensivas americanas en tiempos de Spannocchi y Antonelli. Por su parte quedaba fundada, a fin de dar servicio a la ciudadela, la ciudad homónima, estableciéndose desde entonces como uno de los ejemplos más interesantes de planteamientos urbanísticos formulados en América. Desde sus orígenes y hasta finales del siglo XIX tanto sus proyectistas como moradores manifestaron de forma constante su preocupación por constituir la ciudad conforme a patrones modélicos y ordenados. El ingeniero militar Juan de Herrera y Sotomayor será el encargado de disponer la planta fundacional que habría de tener efecto entre los días 10 y 30 de octubre de 1693 cuando quedaba instituida oficialmente la villa. Tanto por el plano como por las actas de fundación hoy conservadas, se hace evidente cómo la ciudad es legataria de los modos urbanísticos que se dieron en época del renacimiento, aún transcurrido más de un siglo de su principal referente, las Ordenanzas de Nueva Población de Felipe II de $1573^{1}$. Como resultado de todo este proceso contamos con una doble fundación urbana y defensiva de finales del Seiscientos, aunque debida y surgida en base a supuestos de ascendencia humanista.

Sin embargo, numerosos contratiempos lastraron la definitiva construcción de la fortaleza en $1748^{2}$. También lenta fue la formación de la ciudad, que sin embargo quedaba desde sus primeros años definida claramente, delimitada al sur por el río San Juan y al norte por la ciénaga del Yumurí. La naturaleza irregular del terreno obligaba a trazar una ciudad de planta triangular formada por manzanas rectangulares de ocho parcelaciones, en cuyo vértice oeste se ajustaba la plaza de armas fundacional de cara a la rada, de la que arrancaban sus tres principales arterias, las calles Río, Medio y Milanés. Puntuales cambios se dieron a lo largo del siglo XVIII. El principal lo determinó la supresión parcial de la plaza de la iglesia, que pasaba a partir de 1730 a contener la parroquia tras su reconstrucción, arruinada la anterior tras el paso de un huracán. También, aunque sin alterar la traza original, se levantaría en la desembocadura del San Juan en 1741 el fuerte de San José de la Vigía, tomando parte de la plaza de armas ${ }^{3}$.

${ }^{1}$ GARCÍA SANTANA, Alicia: Matanzas. La Atenas de Cuba, Ciudad de Guatemala, 2009, pp. 18-32.

${ }^{2}$ Cfr. CASTILlO MELÉNDEZ, Francisco: La defensa de la Isla de Cuba en la segunda mitad del siglo XVII, Sevilla, 1986, pp. 328-356; HERNÁNDEZ GODOY, Silvia: El Castillo de San Severino: insomne caballero del puerto de Matanzas (1689-1898), Matanzas, 2006.

${ }^{3}$ ESCALONA, Martha S. y HERNÁNDEZ, Silvia T.: "El urbanismo temprano en la Matanzas intrarríos (1693-1800)", Arquitectura y Urbanismo, Vol. XXXII, 1, 2011, pp. 4045; GARCÍA SANTANA, Alicia: Matanzas. La Atenas..., op.cit., pp. 36-43. 
Los renovados aires que traerá consigo el auge del comercio azucarero, una vez Matanzas se convierta en uno de los principales puertos exportadores del género, acabará por definir finalmente el trazado urbano de la ciudad contemporánea. La revalorización de su suelo promoverá la renovación de sus inmuebles, transformando desde los años finales del XVIII las modestas construcciones que hasta el momento habían sido hogar de humildes labriegos y de la tropa de San Severino: "el número de casas que fabricamos entonces fueron 232, todas casi de teja y cantería, y de una regular Arquitectura. Se repartieron 500 solares, se introdujeron los talleres de las artes, abundaron los mantenimientos, y en todo hubo indicio de general transformación”. Estas cifras tenían un claro reflejo demográfico: "La población general participó de tan favorable progreso; pues de 7233 almas que, como ya se ha dicho, constaba antiguamente [población rural incluida], pasó al número de 11552 los que en vez de miserias o escaseces, pasaron a gozar de la abundancia, comodidades y de los bienes de la vida"4.

Ya el primer proyecto de Herrera permitía la fácil ampliación de la ciudad multiplicándose ordenadamente el número de manzanas tierra adentro. Sin embargo, el centro neurálgico lo constituía la plaza de la Vigía, epicentro comercial donde acabarían construyéndose el edificio de la aduana y un brazo de muelle 5 . Por ello, durante las primeras décadas de la nueva centuria se centraron los esfuerzos en desecar la ciénaga del Yumurí, anexa a la plaza de la Vigía. Es de este modo como aparece hacia 1818 la barriada de La Marina modificando levemente el trazado original al añadirse nuevos solares entre la margen del Yumurí y la ca1le Milanés 6 .

No obstante, no cejó aquí el impulso de quienes, aún ocupada toda la zona de la Vigía y La Marina, quisieron construir casas en tan cotizado enclave. Esto dio lugar a varios proyectos de nuevas parcelaciones a costa de terrenos ganados al mar, prolongándose el litoral bahía adentro. El primer intento fue a cargo de José María de Miranda, a quien en 1835 se le concede permiso para rellenar parte de la línea de costa para la construcción de nuevas casas. Le sobrevendrá otra tentativa en 1846 al pretender Francisco Rodil abrir parcelaciones en terrenos marítimos entre la desembocadura del San Juan y el muelle. Aunque tampoco fraguó el proyecto, sí definitivamente lo hizo un año más tarde, en 1847, el debido a Simón Oñativia, quien construiría tres casas allí donde no tuvo lugar las ideadas por

${ }^{4}$ Archivo Nacional del Cuba, Leg. 324. Expediente 15644, fol. 105 a 125. 1809/09/22. Transcrito en "Documentos del Siglo XIX", Boletín del instituto de Historia y del Archivo Nacional, t. 65, 1964, pp. 37-40.

${ }^{5}$ Cfr. LÓPEZ HERNÁNDEZ, Ignacio J.: "Las Aduanas de la ciudad cubana de Matanzas", en Experiencias Compartidas. América: Cultura Visual y Relaciones Artísticas. En prensa.

${ }^{6}$ GARCÍA SANTANA, Alicia: Matanzas. La Atenas..., op.cit., pp. 44-49. 
José María de Miranda. A partir de entonces la calle Pavía pasaba a ser el nuevo límite costero en detrimento de la calle de La Marina?

Ocupados todos los terrenos de la superficie intrarríos, comenzaron a colonizarse las tierras al sur del río San Juan y norte del Yumurí, surgiendo las barriadas de Pueblo Nuevo y Versalles. Hay quienes vieron en esta circunstancia un punto medio entre los que codiciaban un lugar en las inmediaciones del puerto y los contrarios a cegar el límite natural de la Vigía. Por otro lado, en los proyectos anteriores no llegó nunca a considerarse la función defensiva que hasta el momento había desempeñado la zona, donde se radicaba el fuerte de San José de la Vigía. Es por esto interesante aportar aquí un nuevo proyecto nunca realizado, pero que supone uno de los ejemplos más curiosos y ambiciosos de cuantos tuvieron lugar para tales propósitos. Se trata de un plano doble titulado "Proyecto de una dársena y bateria para la Ciudad de Matanzas" firmado por el ingeniero militar Carlos Benítez el 18 de diciembre de 1839 y que ha sido localizado en la Cartoteca del Archivo General Militar de Madrid ${ }^{8}$. En él aparecen dos planos, siendo el de mayor proporción el correspondiente a la planta de la dársena proyectada; a su derecha se detalla la traza de la batería contenida también en la representación general anterior. El documento fue realizado de manera muy cuidada, dibujado a plumilla en tinta negra y lavado en tonos grises, amarillo, azul, ocre y rosa. En la esquina inferior derecha consta la rúbrica de su autor, repetida en el dorso del plano donde también aparecen la fecha y el Visto Bueno del Director Subinspector de Ingenieros Mariano Carrillo de Albornoz. Completan la información del plano una explicación con relación numérica de las dependencias de la batería, tres escalas gráficas, y media flecha orientada al norte.

El primer plano representa la línea de costa, lavada en azul, que transcurre desde el Castillo de San Severino, en rosa, y hasta el límite oeste de la denominada playa de judíos. Comprende por tanto las primeras manzanas de la ciudad fundacional al centro y las incipientes vecindades de Versalles y Pueblo Nuevo a norte y sur. El núcleo histórico aparece notablemente simplificado, encontrándonos las primeras manzanas entre Río, Medio y Milanés y las nuevas parcelas de la Marina, así como el edificio de la aduana centrado en la plaza de armas. Desaparecen por su parte el brazo de muelle y la batería de San José, por contenerse en el mismo proyecto sus sustitutos. Será en las costas de Pueblo Nuevo y Versalles donde se centre la principal intervención, al edificarse nuevas manzanas en ambos barrios con tierras ganadas al mar por el oeste. Concretamente se dibujan

\footnotetext{
7 Ídem, pp. 49-54.

${ }^{8}$ España, Ministerio de Defensa, Instituto de Historia y Cultura Militar, Archivo General Militar de Madrid, Cartoteca, CUB-31/08, Proyecto de una dársena y bateria para la Ciudad de Matanzas. En cumplimiento con el acuerdo de difusión pública de los documentos del archivo se adjunta un enlace al portal de la institución: http://www.portalcultura.mde.es/cultural/archivos/
} 
en amarillo 15 parcelaciones o manzanas en la costa de Pueblo Nuevo y 7 en Versalles. De los extremos de ambos terrenos avanzan sobre el mar sendos brazos, uno de muelle por Versalles y otro donde se proyecta la nueva batería por Pueblo Nuevo. Se forma así una embocadura a una bahía artificial de unas 11 hectáreas de superficie dentro de la misma rada natural de Matanzas. Es de esta forma como se ampliaría considerablemente el puerto, posibilitando además que nuevas edificaciones se beneficiaran de él. Por su parte, la construcción de una batería en el nuevo límite oeste de la ciudad, proveía de nuevo de un sistema defensivo específico a la zona residencial, una vez absorbida la antigua Vigía por el sector comercial.

Como decimos, la batería aparece con detalle reflejada en el segundo plano adjunto, encabezado con el título "Proyecto de una Bateria de costa para la dársena de Matanzas". Se representa en la parte baja una planta de la construcción cortada por una línea de puntos A-B que remite a un perfil situado arriba, ambos con sus correspondientes escalas gráficas y lavados en diferentes tonos. Se trata de una batería de planta semicircular dispuesta como remate del brazo de tierra adentrado en el mar. Se orienta al oeste, con cobertura en un ángulo de 180 grados. Al conjunto se accede, según reza, por un "rastrillo de entrada", que lejos de ser el acceso enrejado habitual, se compone de una puerta de tablones de madera de dos batientes. El patio de armas distribuye las diferentes dependencias, presidida por el cuerpo de guardia, pabellón rectangular de mampostería y techumbre de madera con azotea, precedido por un pórtico. En él se contiene una amplia estancia destinada a la tropa, dos cuartos menores para dependencias del oficial y otros dos para el Sargento y los Artilleros. Ya fuera, en un lateral del patio, se situaban la cocina, un hornillo de bala roja y los comunes. La batería propiamente se disponía elevada sobre una plataforma a la que se accedía por dos rampas. Bajo ésta se ubicaban, con acceso desde la plaza, sendas bóvedas para repuesto de munición y pertrechos de artillería, excavándose en el centro un aljibe. La semicircunferencia que traza el muro de la batería lo constituye un grueso parapeto en barbeta de más de 5 metros y medio de espesor de construcción mixta de tierra y cantería, tal y como se observa en el perfil del plano. La cimentación de la sección de parapeto exterior se hunde más de 5 metros bajo el lecho marino, asentando sobre una estructura de pilotaje de madera; desde aquí sube el muro más de 8 metros hasta la cresta del parapeto.

Este proyecto es hasta el momento el primero realizado por Carlos Benítez, del que se conocen al menos otros dos planos fechados en 1848 para propósitos parecidos, realizando sondas marítimas a fin de ampliar el puerto por la Vigía y Pueblo Nuevo, en la línea de las intervenciones ideadas y ejecutadas en años anteriores, aunque desarrollándolas sustancialmente ${ }^{9}$. La diferencia entre

\footnotetext{
${ }^{9}$ GARCÍA SANTANA, Alicia: Matanzas. La Atenas..., op. cit., pp. 145-146.
} 
estos últimos y el que aquí se da a conocer radica en el cariz defensivo del segundo, planteando por otro lado la remodelación urbana de la ciudad como una propuesta abierta, dada la simplificación advertida en su traza. Por su parte, los proyectos de 1848, aun sin abordar la problemática defensiva, sí examinan exhaustivamente la dimensión urbanística de la propuesta, con detalladas mediciones acomodadas a lo que hasta el momento definía el trazado de la ciudad. No obstante, aún sin llegar a tener efecto este proyecto, sirvan estas breves líneas para conocer, a través de uno de los más ambiciosos y característicos, la riqueza y complejidad, tanto urbana como defensiva, de una ciudad que surgió como bastión de la retaguardia habanera y creció convirtiéndose en uno de los principales puntos estratégicos del lucrativo comercio azucarero.

Fecha de recepción: 3 de septiembre de 2014

Fecha de aceptación: 28 de noviembre de 2014

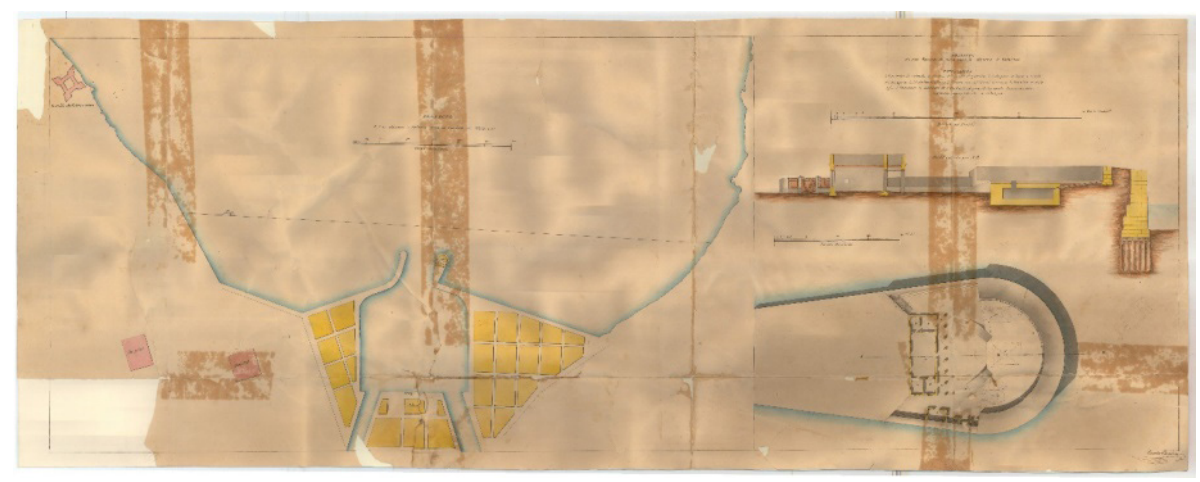

Figura 1. IHCM, AGMM, Cartoteca, CUB-31/08, Proyecto de una dársena y bateria para la Ciudad de Matanzas. Carlos Benítez. 1939. 


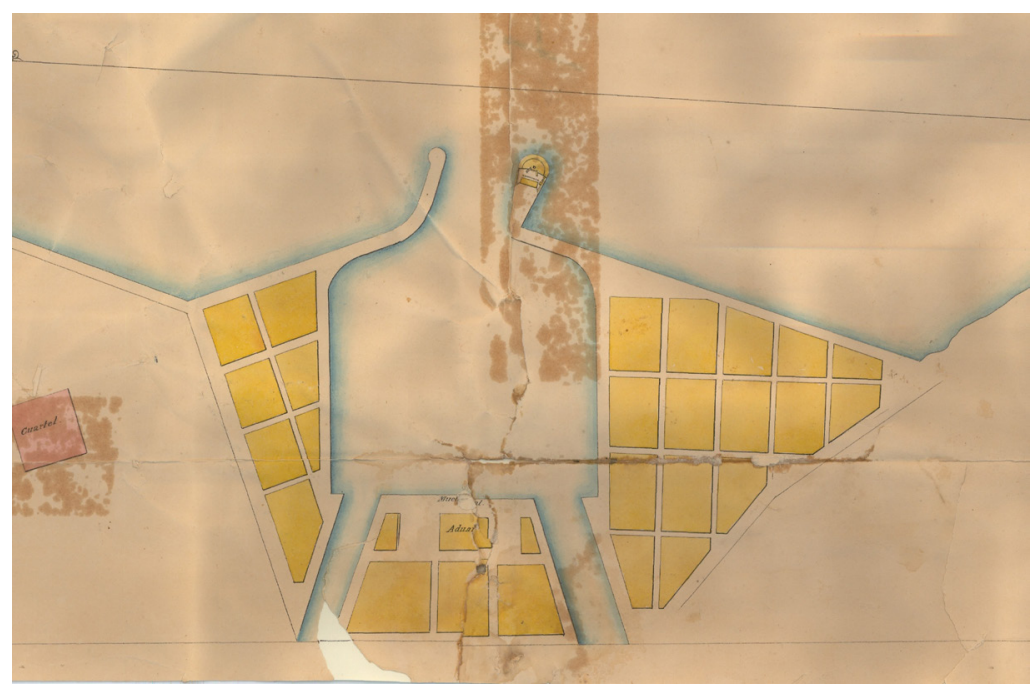

Figura 2. IHCM, AGMM, Cartoteca, CUB-31/08.

Detalle de la planta de la ciudad.

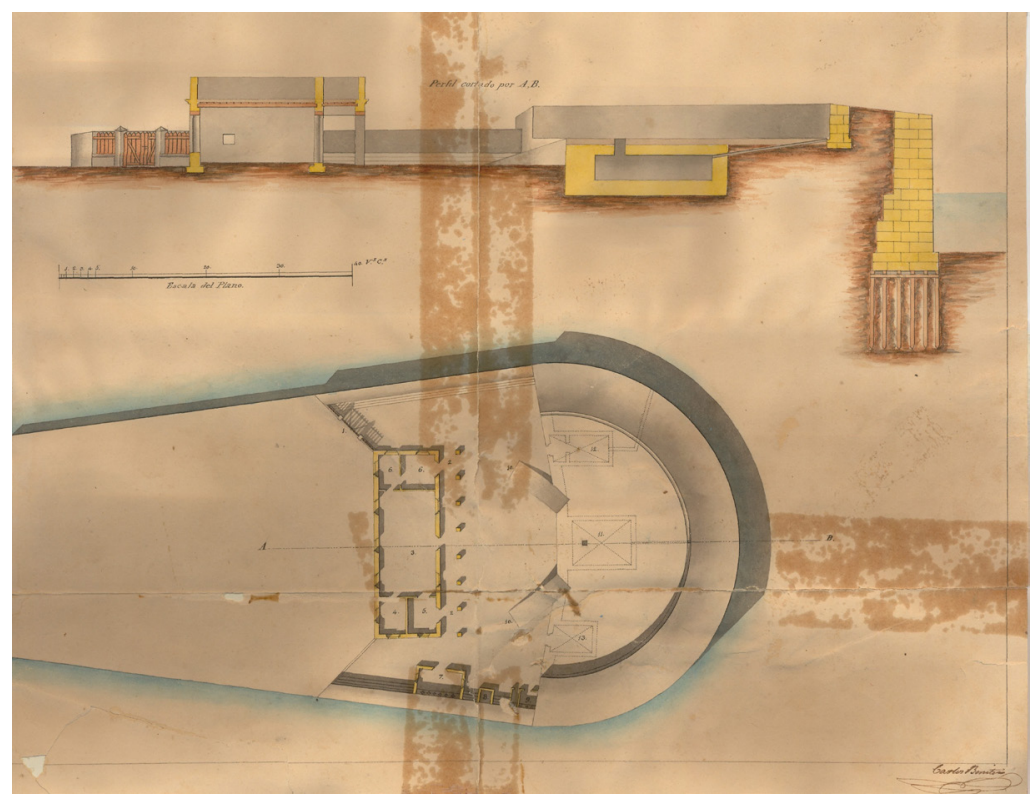

Figura 3. IHCM, AGMM, Cartoteca, CUB-31/08.

Detalle de la planta y alzado de la batería. 